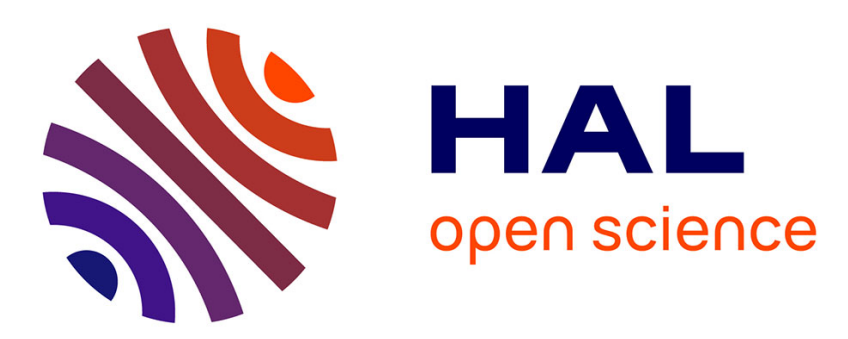

\title{
Electron Mean Free Path Independence of the Glasslike Properties of Polycrystalline Metals
}

\author{
E. Gaganidze, P. Esquinazi
}

\section{To cite this version:}

E. Gaganidze, P. Esquinazi. Electron Mean Free Path Independence of the Glasslike Properties of Polycrystalline Metals. Journal de Physique IV Proceedings, 1996, 06 (C8), pp.C8-515-C8-518. 10.1051/jp4:19968111 . jpa-00254541

\section{HAL Id: jpa-00254541 https://hal.science/jpa-00254541}

Submitted on 1 Jan 1996

HAL is a multi-disciplinary open access archive for the deposit and dissemination of scientific research documents, whether they are published or not. The documents may come from teaching and research institutions in France or abroad, or from public or private research centers.
L'archive ouverte pluridisciplinaire HAL, est destinée au dépôt et à la diffusion de documents scientifiques de niveau recherche, publiés ou non, émanant des établissements d'enseignement et de recherche français ou étrangers, des laboratoires publics ou privés. 


\title{
Electron Mean Free Path Independence of the Glasslike Properties of Polycrystalline Metals
}

\author{
E. Gaganidze and P. Esquinazi \\ Dept. Superconductivity and Magnetism, University of Leipzig, Linnéstrasse 5, 04103 Leipzig, Germany
}

\begin{abstract}
We have measured the sound velocity and attenuation of polycrystalline $\mathrm{Cu}, \mathrm{Al}, \mathrm{Nb}, \mathrm{Nb}_{48} \mathrm{Ti}_{52}, \mathrm{Pt}, \mathrm{Pt}_{70} \mathrm{Rh}_{30}$, $\mathrm{Pt}(1 \% \mathrm{~W}), \mathrm{Pd}, \mathrm{Ta}, \mathrm{NiCr}$ alloy and amorphous $\mathrm{PdSiCu}$ at frequencies $0.1 \mathrm{kHz}<v<20 \mathrm{kHz}$ and at temperatures 40 $\mathrm{mK}<\mathrm{T}<10 \mathrm{~K}$. All polycrystalline samples show acoustic properties which resemble those of dielectric glasses. Their electrical resistivity is in the range $10^{-10} \Omega \mathrm{m}<\rho<10^{-5} \Omega \mathrm{m}$ with an estimated electron mean free path of $10^{-10} \mathrm{~m}<l<10^{-5} \mathrm{~m}$. Our results indicate no correlation between the tunneling system density of states or coupling constant and the electron mean free path, supporting earlier work on the absence of electron assisted relaxation rate. For polycrystalline metals we found that the ratio $\mathrm{T}_{\mathrm{co}} / \mathrm{v}^{1 / 3} \sim(0.006 \pm 0.002) \mathrm{K} / \mathrm{Hz}^{1 / 3}$ in agreement with dielectric glasses $\left(T_{c o}\right.$ is the temperature at the sound velocity maximum).
\end{abstract}

\section{INTRODUCTION}

The acoustic properties of polycrystalline metals at temperatures $T<10 \mathrm{~K}$ resemble those of dielectric glasses, sometimes even quantitatively. This surprisingly experimental fact was found in a large number of polycrystalline metals of different crystal size as well as impurity concentration [1,2]. The anomalies in the acoustic properties, i.e. a maximum in the sound velocity as well as the temperature dependence and absolute value of the internal friction, can be understood assuming the interaction of phonons with tunneling two-level systems (TS) [3,1] which origin is not yet clarified. The acoustic anomalies depend on the energy distribution of the TS density of states and on the coupling between phonons and TS. This coupling enters in the relaxation rate of the TS. Early work on amorphous metals as PdSiCu [4] as well as amorphous superconductors [5] indicates that the TS interact with conduction electrons in a way which is not completely understood at present, although new theoretical ideas may provide a solution to this problem [6,7]. Recently published work on pure $\mathrm{Pt}, \mathrm{Al}$ and $\mathrm{Ta}$ in the superconducting and normal states revealed the absence of electron-assisted relaxation in polycrystalline metals. Because the electron mean free path is the electronic property with the largest difference between an amorphous and a polycrystalline metal, it has been speculated [8] that polycrystals with very small mean free path may show the interaction of TS with conduction electrons as amorphous metals do. The aim of this work is the systematic study of the acoustic properties of a large number of polycrystalline metals with electronic mean free path that ranges from a few $\mu \mathrm{m}$ to a few Amgstrongs in order to search for a possible correlation between the acoustic anomalies and the mean free path.

\section{EXPERIMENTAL DETAILS AND SAMPLES}

The acoustic properties were measured with the vibrating wire and vibrating reed technique in the first resonance mode (flexural vibration) [1]. Because the sound dispersion of amorphous solids and polycrystalline metals [1] depends on the acoustic intensity (strain) [1] due to the interaction with TS, the 


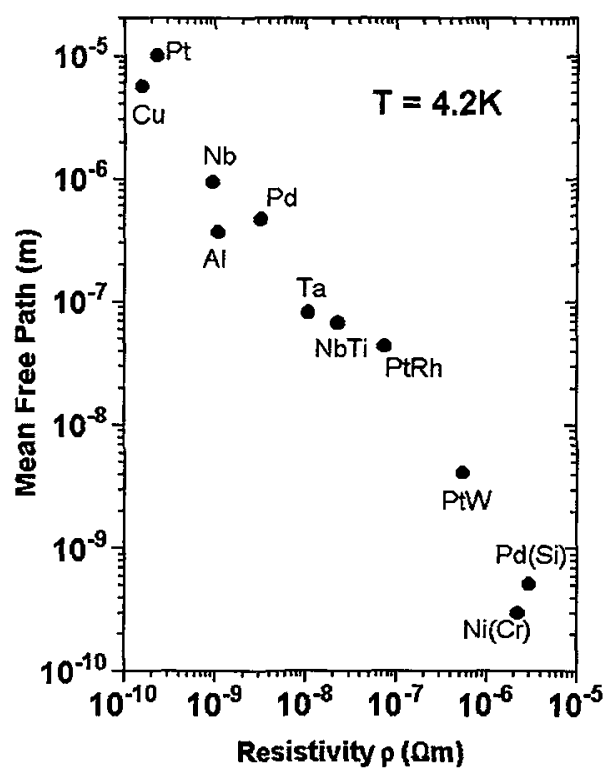

Figure 1: Estimated electronic mean free path as a function of the measured resistivity at $4.2 \mathrm{~K}$ for all the measured samples. Pd(Si): amorphous PdSiCu. Ni(Cr): NiCrAlSiFeMn.

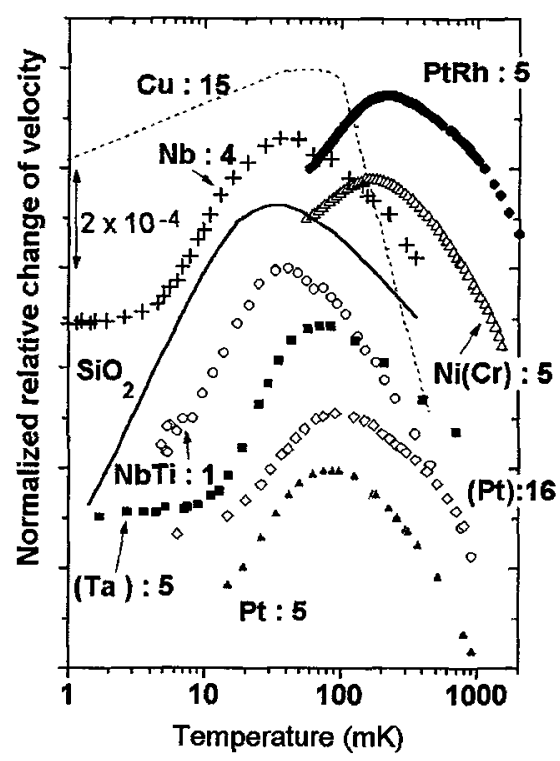

Figure 2: Relative change of sound velocity as a function of temperature for different samples. The y-axis scale must be divided by the number at the right of the sample symbol. The continuous curve corresponds to vitreous silica $\mathrm{SiO}_{2}$ obtained from Ref. [1], "dividing" number : 1 .

maximum strain has been calculated from the reed or wire amplitude and has been taken into account for the comparison of the data from different samples. Measurements have been performed as a function of temperature at constant driving force. Measurements at constant strain provided essentially the same results. Typical dimensions of the reeds were: length $\sim 7 \mathrm{~mm}$, width $\sim 1 \mathrm{~mm}$ and thickness $\sim 50 \mu \mathrm{m}$. We have measured cylindrical wires with diameters between $5 \mu \mathrm{m}$ and $250 \mu \mathrm{m}$. No correlation has been found between the diameter and the acoustic anomalies. A recently published study [8] of a possible contribution of the clamping of the sample to the acoustic properties indicate that this has no influence on the sound dispersion. The clamping, however, influences slightly the absolute value of the internal friction ( $20 \%$ ) but does not change its temperature or the strain dependence in our temperature range.

The measured resistivity and the estimated mean free path of the samples are shown in Fig.1. Except $\mathrm{Pd}_{77.5} \mathrm{Si}_{16.5} \mathrm{Cu}_{6}$, all samples were polycrystalline and commercially available with an impurity concentration between $1 \mathrm{ppm}$ and $1000 \mathrm{ppm}$ (for the pure metals). The sample $\mathrm{Ni}_{74.5} \mathrm{Cr}_{20} \mathrm{Al}_{3.5} \mathrm{Si}_{1} \mathrm{Fe}_{0.5} \mathrm{Mn}_{0.5}$ $(\mathrm{Ni}(\mathrm{Cr})$ in Figs. 1 and 2) has the largest resistivity and a mean free path comparable with that of amorphous metal PdSiCu.

\section{RESULTS AND DISCUSSION}

Figure 2 shows the temperature dependence of the relative change of sound velocity $v(T)-v\left(T_{0}\right) / v\left(T_{0}\right)\left(T_{0}\right.$ some arbitrary temperature) for some of the samples we have measured (strain-range $10^{-7}<\varepsilon<10^{-5}$ ). All polycrystalline metals showed the same anomaly: a maximum in the sound velocity with quasi logarithmic slopes $(\sim \mathrm{C} \ln \mathrm{T})$ above and below it. For comparison we show in Fig. 2 the results for vitreous silica $\mathrm{SiO}_{2}$ taken at $400 \mathrm{~Hz}$ [1]. It is important to note that the magnitude of the anomaly in the sound velocity, i.e. the value of the parameter $\mathrm{C}$ which is proportional to the density of states of TS and the 


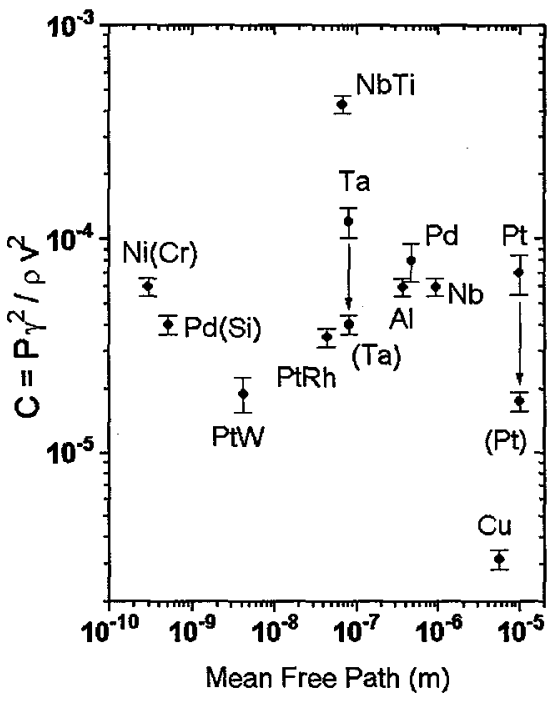

Figure 3: The parameter $\mathrm{C}$ proportional to the density of states of TS (P) as a function of the electron mean free path for different polycrystalline metals. $C \sim 2.10^{-4}$ for vitreous silica. The arrows indicate the decrease of $\mathrm{C}$ after annealing.

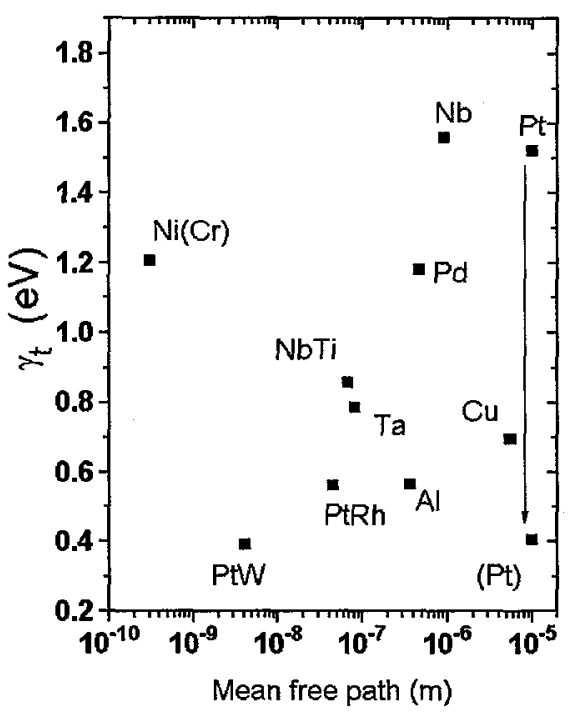

Figure 4: Transversal phonon-TS elastic constant as a function of the electron mean free path. The arrow indicates the maximum decrease of the coupling constant after annealing in Pt [8].

coupling constant square $[1,3]$, depends on the thermal treatment of the sample. The samples (Ta) and $(\mathrm{Pt})$, which results are shown in Fig. 2, were annealed [1,8]. The anomaly vanishes within the resolution of the experiment for longer time or higher annealing temperatures. Note that after annealing the samples remain polycrystals as shown by X-rays [9]. This effect was also observed in amorphous metals [10]: with annealing one can strongly diminish the anomalies in the acoustic properties by relaxing the amorphous structure without crystallisation. This behaviour of the acoustic properties with annealing is in very good agreement with thermal conductivity and specific heat measurements [10]. Therefore we stress that amorphousness or polycrystallinity are neither necessary nor sufficient conditions for the existence of glasslike anomalies at low temperatures.

The results shown in Fig. 2 indicate that the glasslike anomalies of polycrystals can be compared with those of amorphous dielectrics. According to the standard tunneling model the combination of resonant and relaxation interaction between phonons and TS results in a maximum of the sound velocity at $\omega \tau_{\mathrm{m}}$ $\sim 1$, being $\omega$ the phonon frequency of the measurement and $\tau_{\mathrm{m}}$ the minimum relaxation time of the TS at a given temperature. Following the theory of TS-electron interaction $[3,4,7]$ we would expect no maximum in the sound velocity below $1 \mathrm{~K}$. From the slopes of the sound velocity above the maximum we obtained the parameter $\mathrm{C}=\mathrm{P} \gamma^{2} / \rho v^{2}$ (P is the density of states of TS, $\gamma$ the coupling constant between phonons and TS, $\rho$ the mass density and $v$ the sound velocity). The parameter $C$ is plotted in Fig. 3 as a function of the electron mean free path for different samples. Clearly, there is no correlation between $\mathrm{C}$ and the electron mean free path. Note that low temperature thermal treatment (compared with the melting temperature, e.g. $5 \mathrm{~h}$ at $1000 \mathrm{C}$ for $(\mathrm{Pt}$ )) of as-received samples does not change dramatically the value of $\mathrm{C}$ (see Fig.3), therefore the comparison of as-received polycrystalline metallic samples is justified.

From the position of the maximum in the sound velocity at $T_{\mathrm{co}}$ and taken into account that $\tau_{\mathrm{m}}^{-1} \sim \gamma^{2}$, $\mathrm{T}^{3}{ }_{\mathrm{co}}$ according to the standard tunneling model [3], we can estimate the coupling constant $\gamma_{\mathrm{r}}$. This coupling constant is shown in Fig. 4 as a function of the mean free path. We do not observe any correlation between these two quantities. It is interesting to note that for different polycrystalline metals the coupling 


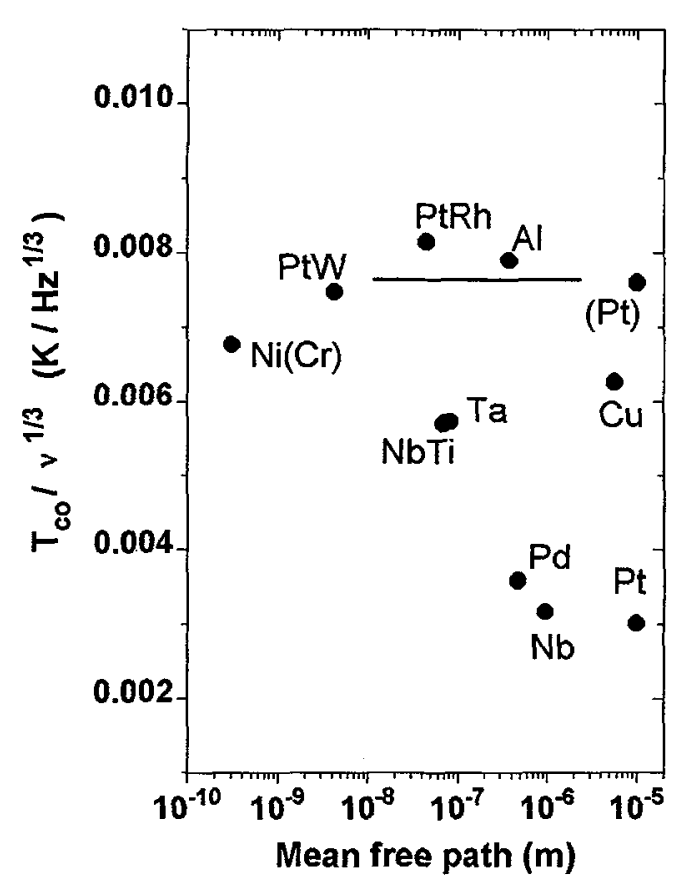

Figure 5: Ratio between the temperature of the sound velocity maximum and the phonon frequency as a function of the mean free path for different polycrystalline metals. The solid line indicates the value obtained for vitreous silica [1]. constant, calculated as described above, changes within a factor of 4, see Fig. 4.

The relaxation rate of the TS through the interaction with phonons (one-phonon process) is given by the relation $\tau_{\mathrm{m}}{ }^{-1}=\mathrm{A} \mathrm{E}^{3}$ $\operatorname{coth}(E / 2 k T)$ with the constant $A \propto \gamma^{2} / v^{5} \rho$ $\propto T_{c o} / v^{1 / 3}$. Figure 5 shows this ratio as a function of the mean free path for the different metals. It is interesting to note that this ratio (proportional to the constant $\mathrm{A}$ ) is equal to $(0.006 \pm 0.002) \mathrm{K} / \mathrm{Hz}^{1 / 3}$. This result indicates that the coupling between phonons and TS in polycrystalline metals is slightly better given by the prefactor of the relaxation rate. The average value obtained for this ratio is in good agreement with that obtained for dielectric glasses; as an example we show in Fig. 5 the value for vitreous silica (solid line in the figure).

\section{CONCLUSIONS}

In summary we have measured the acoustic properties of different polycrystalline metals at low temperatures to search for a possible correlation between the electronic mean free path and the glasslike acoustic anomalies. Our results indicate no correla-

tion and the absence of electron assisted relaxation rate in polycrystalline metals.

\section{ACKNOWLEDGEMENTS}

This work is supported by the Deutsche Forschungsgemeinschaft under Grant DFG Es 86/2-2.

\section{REFERENCES}

[1] P. Esquinazi, R. König, F. Pobell, Z. Phys. B87 (1992) 305-321.

[2] P. Esquinazi, R. König, D. Valentin, F. Pobell, J. Alloy and Compounds 211-212 (1994) 27-32.

[3] See for example: S. Hunklinger and A. K. Raychaudhuri, in Progress in Low Temperature Physics, ed. by H. Brewer (Elsevier, New York, 1986), Vol IX.

[4] B. Golding, J. Graebner, A. Kane, J. Black, Phys. Rev. Lett. 41 (1978) 1487-1990.

[5] P. Esquinazi, H.-M. Ritter, H. Neckel, G. Weiss, S. Hunklinger, Z. Phys. B64 (1986) 81-93.

[6] K. Vládar, A. Zawadowsky, Phys. Rev. B28 (1983) 1564-1596.

[7] Yu. Kagan, N. Prokof'ev, Solid State Commun.65 (1988) 1385-1388.

[8] R. König, P. Esquinazi, B. Neppert, Phys. Rev. B51 (1995) 11424-11432.

[9] H.Ch. Semmelhack, R. König, P. Esquinazi, unpublished.

[10] P. Esquinazi, J. Luzuriaga, Phys. Rev. B37 (1988) 7819-7831. 